\title{
Article
}

\section{Capacity, Mental Mechanisms, and Unwise Decisions}

Thornton, Tim

Available at http://clok.uclan.ac.uk/4356/

Thornton, Tim ORCID: 0000-0002-0137-1554 (2011) Capacity, Mental Mechanisms, and Unwise Decisions. Philosophy, Psychiatry, \& Psychology, 18 (2). pp. 127-132. ISSN 1086-3303

It is advisable to refer to the publisher's version if you intend to cite from the work. http://dx.doi.org/10.1353/ppp.2011.0021

For more information about UCLan's research in this area go to http://www.uclan.ac.uk/researchgroups/ and search for < name of research Group>.

For information about Research generally at UCLan please go to http://www.uclan.ac.uk/research/

All outputs in CLoK are protected by Intellectual Property Rights law, including Copyright law. Copyright, IPR and Moral Rights for the works on this site are retained by the individual authors and/or other copyright owners. Terms and conditions for use of this material are defined in the policies page.

\section{CLoK}

Central Lancashire online Knowledge www.clok.uclan.ac.uk

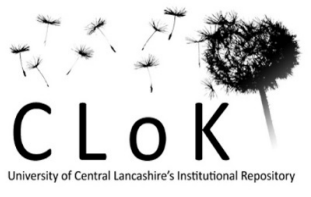


Full Title: $\quad$ Capacity, mental mechanisms and unwise decisions

Short title: Capacity, mechanisms, unwise decisions

Authors (i.e. name as it should appear on the paper):

Tim Thornton

Position (i.e. job description as it should appear on the paper):

Tim Thornton

Professor of Philosophy and Mental Health

Address for correspondence:

International School for Communities, Rights and Inclusion University of Central Lancashire

Preston

PR1 2HE

Other Contact Details:

phone 01772895412

fax 01772892964

email:

TThornton1@uclan.ac.uk

Key-words (not appearing in title):

Judgement, guidance, information, practice

Word count (excluding title page but including references):

$\sim 3,700$

Character count (abstract):

Software used: Microsoft Word

Filename(s): 


\section{Capacity, mental mechanisms and unwise decisions}

\section{Tim Thornton}

Author submitted version of Thornton, Tim (2011) 'Capacity, mental mechanisms and unwise decisions' Philosophy Psychiatry and Psychology 18: 127-32

\section{Introduction}

The notion of capacity implicit in the Mental Capacity Act is subject to a tension between two claims. On the one hand, capacity is assessed relative to a particular decision. It is the capacity to make one kind of judgement, specifically, rather than another. So one can have capacity in one area whilst not having it in another. On the other hand, capacity is supposed to be independent of the 'wisdom' or otherwise of the decision made. ('A person is not to be treated as unable to make a decision merely because he makes an unwise decision.' [Department of Constitutional Affairs 2005: section 1].) One may have capacity even if the decision one arrives at is seen as unwise by one's doctor. In this short note I will explore this tension.

By saying that there is a tension between these two claims, I do not mean that they are inconsistent. They can both be true. But there is a natural way of thinking about the first claim, suggested by the second, which is false and accommodating both in its absence puts limits on just how atomic or decision specific capacity can be.

\section{Capacity as the status of a process}

Distinguishing between a lack of capacity and the making of unwise decisions helps escape the threat of medical paternalism. One can imagine a worry like this. Decision making capacity is assessed by the medical profession. Thus if a subject differs in her decisions from those thought best by her doctors, she is likely to be deemed, by that very fact, to lack the capacity to make that decision. Thus patient autonomy is undermined. One is likely only to be granted the status of having decision making capacity if the values expressed by one's choices accord with those of the medical profession. And hence the possibility of autonomous divergence is undermined.

That worry can be addressed by distinguishing between a lack of capacity and making merely an unwise decision. That in turn suggests a notion of capacity which is distinguished from its outputs. Thus if capacity is not to collapse into the wisdom of the decision made, it is hard to see how else it can be construed except as a matter of using the right decision making process. If it is not a matter of correct outputs, it must instead be the correct process.

But this suggests a problem. How, independently of the actual outcomes of the process, is the process itself to be, first, characterised and, second, assessed? This is not to say that the outcomes need have no epistemic role. They may serve as evidence for (the identification of) the process. Still, if a decision making process (rather than the wisdom of the outcome) is to underpin the status of capacity, there had better be a way to characterise it which is independent of each output decision.

In the next section, I will outline the characterisation of process implicit in the Mental Capacity Act. I will suggest that it may seem to motivate, or justify, or presuppose the idea that a mental process (underpinning capacity) is itself realised, of processed, by a mental mechanism. If the process is the process of a mechanism then it makes sense to say that the process can be independent of its output choices. But, as I will argue in the section after that, there are arguments drawn from Wittgenstein to criticise the very idea of a mental mechanism. Thus there is reason to question the principled distinction between process and output.

\section{The process as suggested by the act}

The Mental Capacity Act substantiates this notion of process in the following claims: 
[A] person is unable to make a decision for himself if he is unable-

(a) to understand the information relevant to the decision,

(b) to retain that information,

(c) to use or weigh that information as part of the process of making the decision, or

(d) to communicate his decision (whether by talking, using sign language or any other means). ' [Department of Constitutional Affairs 2005: section 3]

Not all of these, however, seem equally useful in specifying a process-based condition for decision making capacity. (Logical neatness would be provided by a stipulation of individually necessary and jointly sufficient conditions although there is no need to assume that that is the Act's intent.)

Condition (a) seems a plausible necessary condition. Unless one can understand relevant information, how can one exercise epistemic responsibility? Further, it feeds naturally into (c) insofar as such (successful) understanding would be irrelevant if the decision in question were not actually based on it. But then, given (a) and (c), (b) now seems to be an unnecessary addition to the list. That is not to say that the condition it outlines is not necessary: the retention of information for sufficiently long, at least, to make the decision. But it now seems to be implicit in (c) since how could a decision be based by the subject on the relevant information understood in (a) if it were not retained long enough? Thus stipulating (b) looks to be unnecessary.

Condition (d) seems to be both peripheral and false. Undiagnosed sufferers of 'locked in syndrome' (confused perhaps with those in persistent vegetative state) may be unable to communicate their decisions to medical staff but it is implausible to say that that contingent fact undermines their capacity to make decisions. Of course, the inability in such a case is relational. The sufferer could communicate with the right (suitably informed) audience. What of cases where the inability depends only on the state of the subject herself, such that she could not communicate with anyone?

Such a construal seems to make the condition irrelevantly weak since arguments for the necessity of the possibility, at least, of communication typically concern the possibility of possessing intentional states at all [e.g. Davidson 1984, Dennett 1987, Strawson]. In effect, on the assumption that such arguments for the necessity of the possibility of communication are successful then condition (d) threatens to undermine the decision making capacity only of those without minds. That hardly needs saying. (To repeat: there is no reason to assume that the Act aims at an individually necessary and jointly sufficient condition to analyze capacity. There is, after all, a practical reason to deem a subject to be lacking in capacity if he or she cannot communicate. But that shows that condition (d) is of no help in explaining what is meant by 'capacity'.)

Thus for the purposes of specifying a plausible outcome-independent process of decision making conditions (a) and (c) seem to be central. But now it is worth considering whether (a) makes a separable contribution to the condition. One can imagine a case where (a) is satisfied without (c). Perhaps, for example, one can grasp behavioral information about an estranged lover sufficiently for it to feature as a premise in a variety of mundane arguments but not in the case of an argument to evaluate their continuing love. In that one context, wishful thinking undermines one's ability to reason on the basis of such behavioral information.

But when (c) is satisfied, can (a) not be? That is, can the information be weighed as part of a decision making process without being understood? That seems doubtful. Note also that capacity is supposed to be assessed relative to a particular decision. Thus the relevant information need not be able to play a full inferential role across the board. It need not be fully inferentially promiscuous. Any reading of (a) that requires that cannot fit this constraint on capacity.

It seems, therefore, that condition (c) does all the work. One has capacity if it is satisfied and lacks it if it is not. How much does it help, however, with the specification of an output- 
independent process? At first sight it seems that it does. The decision making process can be thought of as, in part at least, a matter of 'weighing information'. An ability to weigh information might contribute to an ability to make decisions even if, perhaps because of the poor quality of the input information, it leads in any particular case to an unwise outcome. Further it suggests that forming a decision is the result of the operation of a mental mechanism, responsible for weighing information, and that looks to be able to underpin a distinction between capacity and arriving at wise decisions. Providing one embodies the right mechanism, one can have capacity even if one makes unwise decisions.

But whilst the idea of weighing information suggests that the process of forming a decision is mechanical it is so far merely a metaphor which needs further fleshing out. Further, there is a constraint to its fleshing out. For the end decision to be epistemically rational, the weighing of information has to be part of the process. This presents a challenge: what is the difference between information being weighed and then a decision being made (independently of it) and the decision being made on the basis of the weighing of information? The information has normatively to constrain the outcome but, as I will now suggest, there are good reasons drawn from Wittgenstein, to think that meeting this constraint through the idea of a mental mechanism fails.

\section{Are mental processes performed by mental mechanisms?}

Wittgenstein discusses the attractions and problems of the idea that mental processes are underpinned by mental mechanisms. I will outline two kinds of argument against such mechanisms. One kind, exemplified in a discussion of reading and of the feeling of being guided, concerns whether there is ever conscious experience of a mental mechanism which makes the difference between reading and not reading or being guided and not being. The second argument concerns whether a mental mechanism could play an explanatory role in being guided by a rule. Both kinds of argument count against the idea of mental mechanisms and thus count against this way of distinguishing between capacity and the making of wise decisions.

I will start with the example of reading aloud. That process involves saying something on the basis of the text (to put things clumsily to make the parallel with condition (c) above clearer). One is inclined to think that there must be a fundamental difference in the underlying process between someone who can read fluently, can act as a reliable kind of 'reading machine', and someone less able who is still struggling to learn to read. They must embody different processes.

A person, let us say an Englishman, has received at school or at home one of the kinds of education usual among us, and in the course of it has learned to read his native language. Later he reads books, letters, newspapers, and other things.

Now what takes place when, say, he reads a newspaper?--His eye passes--as we say-along the printed words, he says them out loud--or only to himself; in particular he reads certain words by taking in their printed shapes as wholes; others when his eye has taken in the first syllables; others again he reads syllable by syllable, and an occasional one perhaps letter by letter.--We should also say that he had read a sentence if he spoke neither aloud nor to himself during the reading but was afterwards able to repeat the sentence word for word or nearly so.--He may attend to what he reads, or again--as we might put it--function as a mere reading-machine: I mean, read aloud and correctly without attending to what he is reading; perhaps with his attention on something quite different (so that he is unable to say what he has been reading if he is asked about it immediately afterwards).

Now compare a beginner with this reader. The beginner reads the words by laboriously spelling them out.--Some however he guesses from the context, or perhaps he already partly knows the passage by heart. Then his teacher says that he is 
not really reading the words (and in certain cases that he is only pretending to read them).

If we think of this sort of reading, the reading of a beginner, and ask ourselves what reading consists in, we shall be inclined to say: it is a special conscious activity of mind...

But I want to say: we have to admit that--as far as concerns uttering any one of the printed words--the same thing may take place in the consciousness of the pupil who is 'pretending' to read, as in that of the practised reader who is 'reading' it. The word "to read" is applied differently when we are speaking of the beginner and of the practised reader.--Now we should of course like to say: What goes on in that practised reader and in the beginner when they utter the word can't be the same. And if there is no difference in what they happen to be conscious of there must be one in the unconscious workings of their minds, or, again, in the brain.--So we should like to say: There are at all events two different mechanisms at work here. And what goes on in them must distinguish reading from not reading.--But these mechanisms are only hypotheses, models designed to explain, to sum up, what you observe. [Wittgenstein $1953 \S \S 156]$

Wittgenstein here suggests that although one may be drawn to postulate a difference in mental mechanism, the conscious experience of the two readers (the skilled reader and the mere starter), may be the same. Thus as far as conscious experience is concerned, the same mental mechanism - the same experiences - may lead to different outcomes.

In the case of reading, the mental process has at its heart the idea of being guided in what one says (or thinks) by printed letters. Perhaps this notion -guidance - can be used to characterise a mental mechanism independently of its particular outcome. Again there is reason to doubt it.

Make some arbitrary doodle on a bit of paper.--And now make a copy next to it, let yourself be guided by it.--I should like to say: "Sure enough, I was guided here. But as for what was characteristic in what happened--if I say what happened, I no longer find it characteristic."

But now notice this: while I am being guided everything is quite simple, I notice nothing special; but afterwards, when I ask myself what it was that happened, it seems to have been something indescribable. Afterwards no description satisfies me. It's as if I couldn't believe that I merely looked, made such-and-such a face, and drew a line.--But don't I remember anything else? No; and yet I feel as if there must have been something else; in particular when I say "guidance", "influence", and other such words to myself. "For surely,” I tell myself, "I was being guided.”--Only then does the idea of that ethereal, intangible influence arise.

When I look back on the experience I have the feeling that what is essential about it is an 'experience of being influenced', of a connexion--as opposed to any mere simultaneity of phenomena: but at the same time I should not be willing to call any experienced phenomenon the "experience of being influenced". (This contains the germ of the idea that the will is not a phenomenon.) I should like to say that I had experienced the 'because', and yet I do not want to call any phenomenon the "experience of the because".

I should like to say: "I experience the because". Not because I remember such an experience, but because when I reflect on what I experience in such a case I look at it through the medium of the concept 'because' (or 'influence' or 'cause' or 'connexion').--For of course it is correct to say I drew the line under the influence of the original: this, however, does not consist simply in my feelings as I drew the line-under certain circumstances, it may consist in my drawing it parallel to the other-- 
even though this in turn is not in general essential to being guided.- [Wittgenstein $1953 \S \S 175-7]$

There is no evidence from conscious experience of a felt mechanism that links the signs to what one might say or do.

Wittgenstein goes on to suggest that we apply the word 'reading' or 'guidance' on the basis of the performance of a speaker or agent. This is a normative relationship characterising input and output. It is not a mechanical connection between the two. I will return to this idea shortly.

The second kind of argument that Wittgenstein deploys against the idea of mental mechanisms concerns their explanatory possibilities. He considers and rejects the possibility of invoking such a mechanism to explain being guided by a rule using, as one example, the 'plus 2' series, the series of numbers produced by starting at 0 and adding 2 sequentially. Having been suitably taught, children are able to carry this series on to arbitrarily high numbers. They can be said to understand the series, to have gasped it. Such understanding is ascribed despite what might seem to be a lack of evidence: the series - and thus the competence - is infinite whilst the ascription is based on only finite past practice.

According to one commentator, John McDowell, we tend to think of competence in continuing such a series as resulting from a mental mechanism which reliably delivers the right result at each point [McDowell 1984]. The misleading thought is this: postulating a mental mechanism could explain why just the right numbers - out of the multitude of potential wrong numbers - are given for an infinite series. This picture can also be augmented, especially in mathematical cases, with the idea that the mechanism tracks or follows objective, perhaps supernatural, rails which are already out there, independently of us. Our continuing a series is merely going over, in bolder pencil, moves already made.

This line of argument rests on a mistake, however. It goes wrong in the assumption that it is necessary, or even helpful, to postulate a mental mechanism to explain an ability to follow a rule. Postulating such a state of mind is an 'idle wheel' because it cannot ground the kind of expectation that either we, or other people, will continue in the same (successful) way. As Wittgenstein argues, if a direct inference from how someone has made judgements in the past to their future judgements were not reliable, postulating an intervening mechanism would not help either.

In the third person case of ascribing understanding to others, past practice, once described as mere inductive evidence for a mechanism, could be evidence for any number of diverging mechanisms. The same practice could be interpreted as being in accord with any number of different mechanisms. In the first person case there is a problem in specifying the right mechanism to embody. Any real causal mechanism might misfire or breakdown and thus cannot be used to specify the correct continuation of the series. Any abstract representation of a mechanism, or any specification of the series using symbols, will require the correct interpretation which will beg the question.

Despite the attractions, the idea that mental processes are underpinned by mental mechanisms is a misleading one. So to return to the question at the end of the previous section - what is the difference between information being weighed and then a decision being made and the decision being made on the basis of the weighing of information? - whatever answer one gives, it cannot be a matter of specifying a mental mechanism independently of its output. Wittgenstein's positive account of reading suggests instead that the 'process' of reading (if that is a helpful label) is defined by the general ability to get the words right and not by any inner experiences (which is not to deny that there are such experiences, however). The same, I suggest, holds for decision making capacity.

\section{Conclusion: The tension again}

I have suggested that there is a tension between two claims about decision making capacity: 
that it is domain specific and that it is independent of the wisdom or otherwise of its output. A natural way of spelling out the latter is to think of capacity as process-based. That in turn invites the idea that the process is underpinned by a mental mechanism because such a mechanism can distinguish between process and outputs (and hence capacity and the wisdom of a decision).

Arguments drawn from Wittgenstein undermine the latter idea, however, and thus its use to characterise a mental process independent of output. This suggests that the idea of a process of decision making is not a quasi-mechanical one but rather - like the idea of reading - one defined by a certain general ability, an ability or competence generally realised in performance.

If so, the distinction between wisdom and capacity is provided by a partial independence of output from decision making process now construed without reference to mental mechanisms. Any individual decision could be unwise. But at the general level, a capacity reflecting ability to weigh information is an ability generally to make the right decision relative to that information.

I can now summarise the tension implicit in two claims about decision making capacity. There is supposed to be a principled distinction between capacity and wisdom and capacity is supposed to be decision-specific. But if capacity is a matter of the right decision making process and if process cannot be explained through a mental mechanism then the independence of capacity and wisdom can only be partial. The independence is at the level of individual decisions relative to a background of largely using the information correctly. But this means that the idea that capacity is decision-specific has to be limited. A too fine differentiation of decision types undermines the grounds for ascribing capacity if capacity is to be distinguished from wisdom. The generality implicit in capacity puts the idea of decisionspecificity under pressure. Thus there are limits to how much capacity can be understood to be decision-specific.

\section{References}

Davidson, D. 1984. Inquiries into truth and interpretation. Oxford: Oxford University Press

Dennett, D. 1987. The intentional stance, Cambridge, Mass: MIT Press.

Department of Constitutional Affairs. 2005. Mental Capacity Act http://www.opsi.gov.uk/acts/acts2005/ukpga_20050009_en_1

McDowell, J. 1984 Wittgenstein on Following a Rule. Synthese 58: 325-363

Strawson, P. F. 1959. Individuals. London: Methuen.

Wittgenstein, L. 1953 Philosophical Investigations. Oxford: Blackwell 